\title{
Bacterial lipoprotein tolerance attenuates cardiac dysfunction in septic mice
}

\author{
JING ZHOU, MIN HUANG, LI-QING BI, SU-MING ZHOU, YUN-LIN CHENG, GUO-XIAN DING, \\ WEI-HAO SUN
}

Department of Geriatrics, the First Affiliated Hospital of Nanjing Medical University, Nanjing, P.R. China

\begin{abstract}
In order to examine the effect of BLP tolerance on cardiac dysfunction in CLP-induced septic mice, cardiac function was measured via echocardiography at various time points following induction of sepsis by CLP in BLP-tolerant and control C57BL/6 mice. Levels of tumour necrosis factor $\alpha(T N F-\alpha)$, interleukin 10 (IL-10) and Toll-like receptor 2 (TLR2)-myeloid differentiation factor 88 (MyD88)-dependent signaling molecules in the myocardium were also examined. Cardiac function was significantly decreased 6-12 h following CLP-induced sepsis compared with that of sham controls, with cardiac output decreasing from $0.50 \pm 0.06 \mathrm{ml} / \mathrm{s}$ to $0.16 \pm 0.04 \mathrm{ml} / \mathrm{s}$ at $6 \mathrm{~h}$ and $0.57 \pm 0.06 \mathrm{ml} / \mathrm{s}$ to $0.13 \pm 0.02 \mathrm{ml} / \mathrm{s}$ at $12 \mathrm{~h}$, whereas BLP tolerance attenuated CLP-induced cardiac dysfunction at $12 \mathrm{~h}$ following CLP with cardiac output increasing from $0.13 \pm 0.02 \mathrm{ml} / \mathrm{s}$ to $0.26 \pm 0.05 \mathrm{ml} / \mathrm{s}$ at $12 \mathrm{~h}$. TNF- $\alpha, I L-10$ and TLR2MyD88-dependent signaling molecules in the myocardium were not significantly different among BLPtolerant or non-tolerant control groups. These findings suggest that low dose BLP pretreatment can attenuate cardiac dysfunction, increasing the survival rate of septic mice. This effect did not involve $T N F-\alpha, I L-10$ or TLR2-MyD88-dependent cytokines. Bacterial lipoprotein pretreatment attenuated cardiac dysfunction in CLP sepsis. TNF- $\alpha$, IL-10 and TLR2-MyD88-dependent signaling molecules did not contribute to cardiac dysfunction observed in CLP-induced sepsis.
\end{abstract}

Key words: cardiac dysfunction, bacterial lipoprotein, Toll-like receptor 2, sepsis.

(Centr Eur J Immunol 2012; 37 (3): 209-220)

\section{Introduction}

Sepsis results from systemic inflammation and can lead to lethal organ damage. Despite recent advances in antibiotic therapy and intensive care, overall mortality from severe sepsis has exceeded $30 \%$ of the total mortality in the United States [1-3]. Current research has shown that after severe injury or infectious challenges, some patients respond by the activation of proinflammatory signaling pathways and overexpression of inflammatory mediators, resulting in a systemic inflammatory response. This culminates in severe shock, multi-organ failure, and death [4]. Cardiovascular dysfunction is a major consequence of septic shock and contributes to the high morbidity and mortality rates observed in septic patients $[5,6]$. Sepsis-induced cardiovascular dysfunction is characterized by decreased contractility, impaired ventricular response to fluid therapy, and ventricular dilatation [7]. Recent studies have shown that circulating cytokines (TNF- $\alpha$, IL-1 $\beta$ ), lysozyme $c$, or endothelin-1 have direct inhibitory effects on myocyte contractility. Intracellular alterations in calcium flux within the cardiomyocyte can also influence myocyte contractility during sepsis [8]. Despite extensive basic and clinical research, the pathophysiology of myocardial dysfunction associated with septic shock is still poorly understood.

Bacterial lipoprotein (BLP), characterized by a unique $\mathrm{NH}_{2}$-terminal lipo-amino acid, $\mathrm{N}$-acyl- $\mathrm{S}$-diacylglyceryl cysteine, is the most abundant protein in the outer membrane of both gram-positive and gram-negative bacteria. BLP is known to activate monocytes and/or macrophages to produce inflammatory cytokines and to induce apoptosis in experimental animals $[9,10]$. Pre-exposure to BLP induces

Correspondence: Dr. Su-Ming Zhou, Department of Geriatrics, the First Affiliated Hospital of Nanjing Medical University, 300 Guangzhou Road, Nanjing 210029, China, tel. +86-13951014393, fax +86-25-83780170, e-mail: zhousmco@yahoo.com.cn

Dr. Yun-Lin Cheng, Department of Geriatrics, the First Affiliated Hospital of Nanjing Medical University, 300 Guangzhou Road, Nanjing 210029, China, tel. +86-13805188977, fax +86-25-83780170, e-mail: chengyunlin@njmu.edu.cn 
BLP tolerance, which can protect mice against BLP, lipopolysaccharide- (LPS), live bacterial-, and polymicrobial sepsis-induced lethality [11].

Families of the Toll-like receptors (TLRs) are involved in BLP tolerance. TLRs have recently emerged as key components of the innate immune system that detect microbial infection and trigger antimicrobial host defense responses [12]. TLR2 regulates the cellular expression of proinflammatory mediators following BLP stimulation [13]. BLP activates the TLR2 signaling cascade through the TLR2 Toll/IL-1 receptor (TIR) domain, using a conserved signal transduction pathway requiring myeloid differentiation factor 88 (MyD88), IL-1-receptor-associated kinases (IRAKs), tumor necrosis factor receptor-associated factor 6 (TRAF6), I $\mathrm{B}$ kinase kinase (IKK), and nuclear factor- $\kappa \mathrm{B}(\mathrm{NF}-\kappa \mathrm{B})$ to induce tumor necrosis factor- $\alpha$ (TNF- $\alpha$ ) or interleukin (IL)-10 production. Recent studies have shown that modulation of this signaling pathway via TLR2 is involved in the development of BLP tolerance [14, 15]. Pretreatment of human THP-1 monocytic cells with BLP induced tolerance to a second BLP challenge with diminished TNF- $\alpha$ and IL- 6 production. BLP tolerance is associated with reductions in TLR2 and IRAK-1 expression, MyD88-IRAK complex formation and $\mathrm{I} \kappa \mathrm{B}-\alpha$ phosphorylation. However, the role of TLR2 signaling in the tissue response to septic shock in BLP-tolerant mice has not been determined

In the present study, we investigated the protective effect of BLP tolerance in septic shock and examined whether TNF- $\alpha$ and IL-10 production correlates with myocardial dysfunction seen in septic shock. Furthermore, we assessed the effects of a TLR2-mediated signaling pathway in the cardiac parenchymal cells of BLP-tolerant mice.

\section{Material and methods}

\section{Reagents and antibodies}

BLP, a synthetic BLP (Pam3Cys-Ser-(Lys)4•3HCl) was purchased from Alexis Biochemicals (San Diego, CA). Polyclonal antibodies (pAb) for TLR2, IRAK-1, IKK $\alpha$, I $\mathrm{B}-\alpha$ and NF- $\kappa \mathrm{B}$ p65 were obtained from Cell Signaling Technology (Beverly, MA). Anti-MyD88 pAb was purchased from eBioscience (San Diego, CA). Rabbit pAb against TRAF6 (Mid) was obtained from Zymed Laboratories (South San Francisco, CA), mouse pAb for $\alpha$-tubulin was purchased from Sigma-Aldrich (St. Louis, MO), and ELISA tests for mouse TNF- $\alpha$ and IL-10 were performed using commercially available kits (BioSource International, Camarillo, CA). The TUNEL assay kit was purchased from Promega (Madison, WI).

\section{Animals and CLP polymicrobial sepsis model}

Pyrogen-free male C57BL/6 mice (6-8 wk old; $19-26$ g) were obtained from Shanghai SLAC Laboratory Animal CO.
Ltd (PRC).The mice were quarantined and maintained on a standard pellet diet for $1 \mathrm{wk}$ prior to any experiments. All animal procedures were performed in accordance with the standards of the Animal Use and Care Committee of Nanjing Medical University (PRC). Tolerance in mice was induced by injection of $10 \mathrm{mg} / \mathrm{kg}$ BLP (i.p., BLP tolerance) [11], or an equal volume $(200 \mu \mathrm{l})$ of PBS (no tolerance) $24 \mathrm{~h}$ prior to septic challenges. Following BLP tolerance induction, nontolerant and BLP-tolerant mice were subjected to polymicrobial sepsis, which was induced by cecal ligation and puncture (CLP). Briefly, the mice were anesthetized with chloral hydrate, a midline incision was made on the anterior abdomen, and the cecum was exposed and ligated with a 3-0 silk suture. Two punctures through the cecum were made with an 18-gauge needle, and feces were extruded from the holes. The cecum was then returned to the peritoneal cavity and the abdominal incision was closed. Sham-operated mice served as surgical controls; these animals were anesthetized, a midline incision was made, the cecum was exposed for one minute, and the abdominal incision was then closed. After sepsis induction, a single dose of resuscitative fluid (lactated Ringer solution, $25 \mathrm{ml} / \mathrm{kg}$ body weight) was immediately administered at room temperature by subcutaneous injection. There were four groups: the normal control $(\mathrm{N})$, sham control (S), BLP tolerance + CLP $(B+C)$ and CLP $(C)$.

\section{Experimental protocols}

Mice were subjected to CLP at $0 \mathrm{~h}, 2 \mathrm{~h}, 6 \mathrm{~h}$ and $12 \mathrm{~h}$ following CLP; cardiac function measurements were performed as described previously $[16,17]$. To examine the effects of BLP tolerance TLR2-mediated signaling and cardiac myocyte apoptosis, hearts were harvested at 0, 2, 6 and $12 \mathrm{~h}$, respectively. Hearts were washed free of blood using icecold phosphate buffered saline (PBS) and a single tissue section $(5 \mathrm{~mm})$ was taken from each heart at the same anatomical location. The immersion was fixed in $4 \%$ buffered paraformaldehyde, and embedded in paraffin for tissue section preparation. The remaining heart tissue sections were immediately frozen in liquid nitrogen and stored at $-70^{\circ} \mathrm{C}$.

\section{Cardiac function assessment}

Echocardiography was performed using a $13 \mathrm{MHz}$ linear array ultrasound probe (Vivid 7 Dimension, GE Medical, USA) in sedated mice (chloral hydrate, $200 \mathrm{mg} / \mathrm{kg}$, i.p.). Parasternal short- and long-axis views were obtained at the midventricular level, at a frame rate of 483 frames per second and a depth of $1 \mathrm{~cm}$. LV dimensions were measured from the M-mode tracings. Fractional shortening (FS), left ventricle ejection fraction (EF) and cardiac output (CO) were calculated with the use of a customized version of the EchoPac Software (GE Medical). Values obtained in three consecutive cardiac cycles were averaged. CO, FS, EF, and heart rate (HR) were chosen as indices of cardiac function. 


\section{Western blot analysis}

\section{Sample preparation}

Nuclear and cytoplasmic proteins were isolated from the whole heart tissue homogenates using a method described previously [18]. Briefly, myocardial samples were homogenized in $0.7 \mathrm{ml}$ of ice-cold buffer A $(5 \mathrm{mM}$ Trise $\mathrm{HCl} \mathrm{pH}$ 7.4, $150 \mathrm{mM} \mathrm{NaCl}, 5 \mathrm{mM}$ EDTA pH 8.0, 10 mM EGTA pH 8.0, 1 mM dithiothreitol [DTT], protease inhibitor cocktail [Roche Diagnostics, Mannheim, Germany], and phosphatase inhibitors: $50 \mathrm{mM} \mathrm{NaF}, 30 \mathrm{mM}$ $\beta$-glycerophosphate, $1 \mathrm{mM} \mathrm{Na} \mathrm{VO}_{4}$, and $20 \mathrm{mM} \rho$-nitrophenol-Na). Homogenates were centrifuged for $20 \mathrm{~min}$ at $10,000 \mathrm{rpm}$ at $4^{\circ} \mathrm{C}$. Supernatants containing cytoplasmic proteins were collected and stored at $-70^{\circ} \mathrm{C}$. The pellets were suspended in ice-cold buffer B $(5 \mathrm{mM}$ Tris $\bullet \mathrm{HCl}$ pH 7.4, $150 \mathrm{mM} \mathrm{NaCl}, 5 \mathrm{mM}$ EDTA pH 8.0, 10 mM EGTA $\mathrm{pH}$ 8.0, $1 \mathrm{mM}$ DTT, protease inhibitors, phosphatase inhibitors, $10 \%$ Nonidet P-40, 10\% BriJ-35, 10\% deoxycholic acid sodium salt), incubated on ice for $60 \mathrm{~min}$, mixed frequently, and centrifuged for $15 \mathrm{~min}$ at $7900 \mathrm{~g}$ maintained at $4^{\circ} \mathrm{C}$. Supernatants were collected following centrifugation as nuclear extracts and stored at $-70^{\circ} \mathrm{C}$. The concentration of the total protein in each sample was determined using the Pierce protein assay reagent (Pierce Chemical, Rockford, IL).

\section{Western blotting}

Cytoplasmic and nuclear proteins were denatured at $100^{\circ} \mathrm{C}$ for $5 \mathrm{~min}$ in the loading buffer $(60 \mathrm{mM}$ Tris, $2.5 \%$ sodium dodecyl sulfate [SDS], $10 \%$ glycerol, $5 \%$ mercaptoethanol, $0.01 \%$ bromphenol blue). Aliquots containing an equal amount of the total protein from each sample were separated in SDS-polyacrylamide gels and transferred onto immobilon-P membranes (Millipore, Bedford, MA, USA). The membranes were blocked for $1 \mathrm{~h}$ at room temperature with $5 \%$ nonfat milk and probed overnight (maintained at $4{ }^{\circ} \mathrm{C}$ ) with appropriate primary antibodies (pAb) at conditions recommended by the manufacturers (anti-TLR2, anti-MyD88, anti-IRAK1, anti-

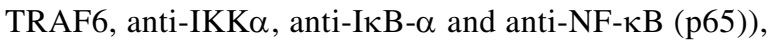
respectively. Blots were then incubated with appropriate horseradish peroxidase-conjugated secondary antibodies at room temperature for $2 \mathrm{~h}$, developed with SuperSignal chemiluminescent substrate (Pierce Chemical, Rockford, IL) and exposed to X-Omat BT films (Kodak). Quantification of the developed target bands was determined by densitometric analysis.

\section{Myocardial cytokine measurements}

TNF- $\alpha$ and IL-10 levels in the myocardial cytoplasmic proteins were determined using commercially available ELISA kits according to the manufacturer's instructions.

\section{In situ apoptosis assay}

In situ cardiac myocyte apoptosis was examined using the TUNEL assay. This assay was performed according to the manufacturer's instructions. Briefly, tissue sections were deparaffinized, rehydrated, fixed and permeabilized, and then incubated with FITC-labelled TdT incubation buffer at $37^{\circ} \mathrm{C}$ for $1 \mathrm{~h}$. Anti- $\alpha$-actinin immunohistochemistry was then performed. Sections were blocked, incubated with primary antibody against $\alpha$-actinin for $1 \mathrm{~h}$ followed by incubation with Cy3-conjugated anti-IgG for 1 h. Hoechest 33342 reagent was then used to counter stain the nuclei. The fluorescence images were observed and captured using a confocal microscope (2-Photon, LSM 510, Zeiss). Five slide fields were randomly examined using a defined rectangular field area with magnification $\times 200$. One hundred cells were counted in each field, and apoptotic cardiac myocytes are presented as the percentage of total cells counted.

\section{Statistical analysis}

Results are expressed as mean \pm SEM. Analysis of variance (ANOVA) was used to assess for differences between groups at each time-point, followed by a Scheffe multiple comparison for post hoc analysis. Differences between groups of relative intensity for western blot analysis were performed with repeated measures by using the randomeffects generalized estimated equation (GEE). $p<0.05$ was specified as statistically significant.

\section{Results}

\section{BLP tolerance prevented cardiac dysfunction in septic mice}

In vivo cardiac function was measured at $0 \mathrm{~h}, 2 \mathrm{~h}, 6 \mathrm{~h}$ and $12 \mathrm{~h}$ after the mice were subjected to CLP via echocardiography. As shown in Figs. 1 and 2, HR, FS and EF were increased between $0 \mathrm{~h}$ and $6 \mathrm{~h}$, and then declined to the baseline at $12 \mathrm{~h}$ in shams. CO was decreased between $0 \mathrm{~h}$ and $2 \mathrm{~h}$, and returned to the baseline at $12 \mathrm{~h}$. In the CLP group, $\mathrm{HR}$ and FS were increased between $0 \mathrm{~h}$ and $2 \mathrm{~h}$, and decreased after $2 \mathrm{~h}$. EF was increased at $2 \mathrm{~h}$ and decreased after $6 \mathrm{~h}$. CO was continuously decreased at $12 \mathrm{~h}$ compared to the baseline. $\mathrm{HR}, \mathrm{FS}, \mathrm{EF}$ and $\mathrm{CO}$ in the BLP tolerance + CLP group were similar to the CLP group between $0 \mathrm{~h}$ and $6 \mathrm{~h}(p<0.05)$. They were then increased after $6 \mathrm{~h}$, which was significantly higher than in the CLP group at $12 \mathrm{~h}(p<0.05$, respectively). Interestingly, BLP tolerance prevented sepsis-induced cardiac dysfunction during the middle stage of sepsis.

\section{Myocardial cytokine production following sepsis}

Changes in TNF- $\alpha$ and IL-10 levels in the myocardial cytoplasmic proteins are shown in Fig. 3 and 4. TNF- $\alpha$ levels in the myocardium at $0 \mathrm{~h}, 2 \mathrm{~h}, 6 \mathrm{~h}$ and $12 \mathrm{~h}$ after CLP were not different from those of the control or sham groups 


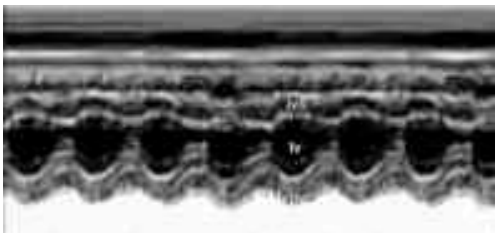

Normal

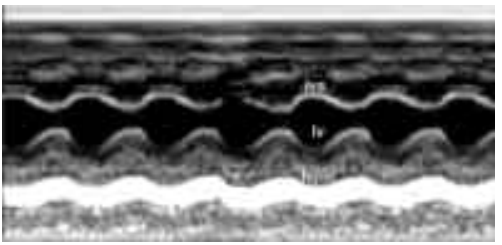

Sham $2 \mathrm{~h}$

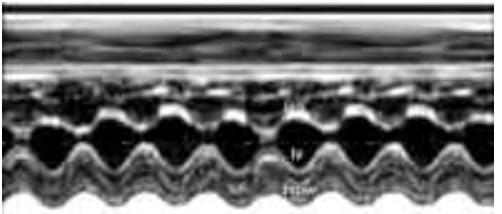

Sham $6 \mathrm{~h}$

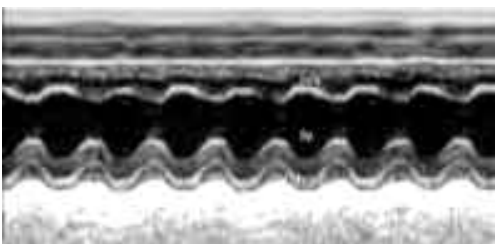

Sham $12 \mathrm{~h}$

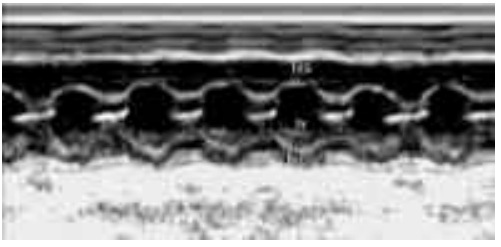

CLP 2 h

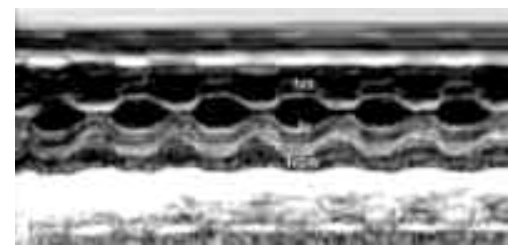

CLP 6 h

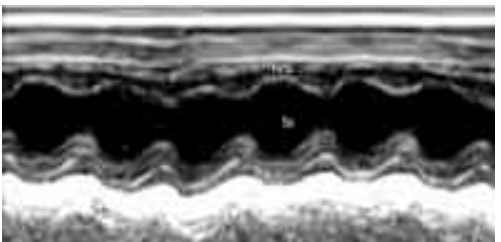

CLP $12 \mathrm{~h}$

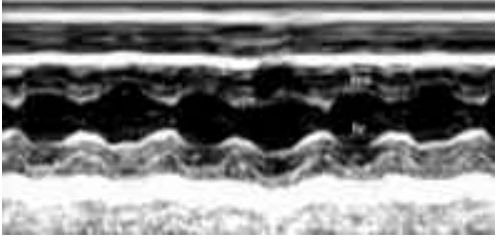

$\mathrm{BLP}+\mathrm{CLP} 0 \mathrm{~h}$

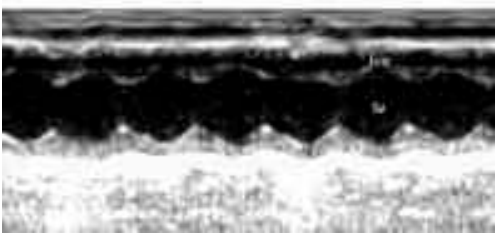

$B L P+C L P 2 h$

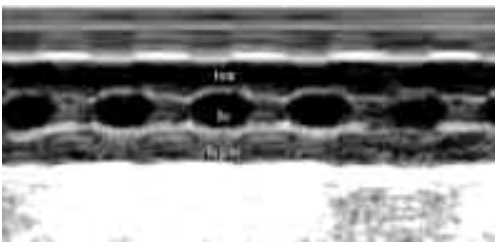

$\mathrm{BLP}+\mathrm{CLP} 6 \mathrm{~h}$

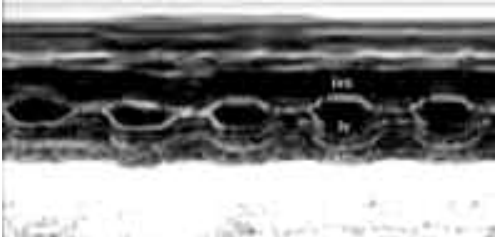

BLP + CLP 12 h

Fig. 1. Echocardiographic assessment of BLP tolerance on cardiac function in CLP-induced septic mice. Representative M-mode echocardiograms in BLP-tolerant and non-tolerant CLP mice at times $0 \mathrm{~h}, 2 \mathrm{~h}, 6 \mathrm{~h}$ and $12 \mathrm{~h}$ after CLP

$(p>0.05) .2 \mathrm{~h}$ after CLP, IL-10 levels in the myocardium were significantly increased in the BLP tolerance + CLP group as compared with levels in the sham group $(p<0.05)$ and in the CLP mice $(p<0.05)$, respectively. However, IL-10 levels were not different at any other time points among the four groups $(p>0.05)$.

Protein expression of TLR2, MyD88, IRAK-1, TRAF6, IKK- $\alpha$, IKB- $\alpha$ and NF-kB (p65) in the myocardium of CLP-induced septic mice

In vitro BLP tolerance developed through the down-regulation of TLR2 expression [12]. We examined myocardial protein levels of TLR2, MyD88, IRAK-1, TRAF6, IKK- $\alpha$, I $\kappa$ B $-\alpha$ and NF- $\kappa$ B (p65) by Western blot analysis in BLPtolerant and non-tolerant septic mice. Figs. 5 and 6 show that BLP pretreatment did not alter TLR2, Myd88, IRAK-1, IKK $-\alpha$ or NF- $\kappa \mathrm{B}$ myocardial expression among the four groups ( $p>0.05$, respectively).
In Fig. 5, the levels of TRAF6 in the myocardium of BLP-tolerant mice at time $0 \mathrm{~h}$ were significantly higher than in the control group, and not markedly different from that in the sham group and non-tolerant CLP mice at times $2 \mathrm{~h}$, $6 \mathrm{~h}$ and $12 \mathrm{~h}$ after CLP.

As shown in Fig. 6, IкB- $\alpha$ level in the myocardium of BLP-tolerant septic mice at the time $12 \mathrm{~h}$ following CLP were significantly increased compared with the levels of the sham and CLP groups. However, there was no significant difference at other time points among the four groups.

\section{Apoptosis in cardiomyocytes is delayed by BLP tolerance}

Apoptosis in mouse cardiomyocytes was measured at $0 \mathrm{~h}, 2 \mathrm{~h}, 6 \mathrm{~h}$ and $12 \mathrm{~h}$ after the mice were subjected to CLP via TUNEL assay. As shown in Fig. 7, there were more apoptotic cells in BLP tolerance than in the normal or the control groups $(p<0.05)$, however after CLP challenge, 


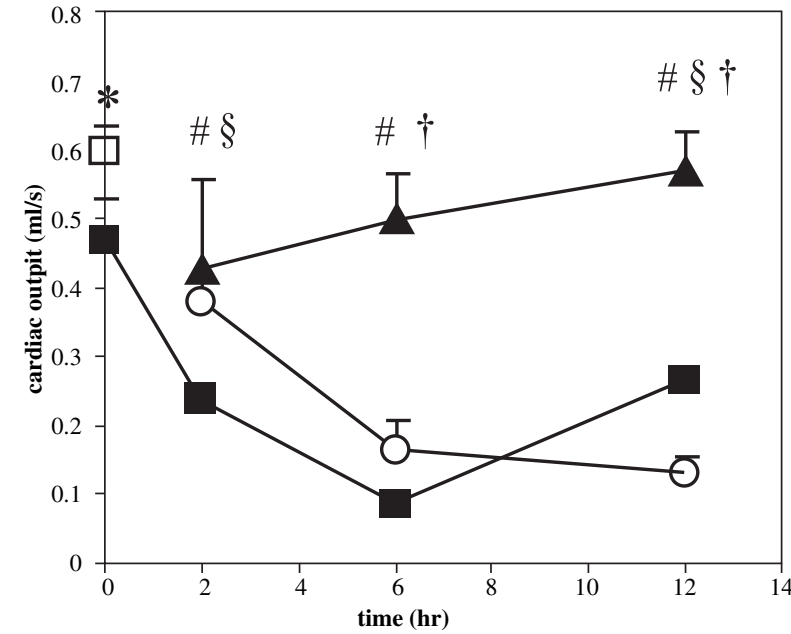

$\neg-\mathrm{N} \quad \longleftarrow$ sham $\quad-\mathrm{O}-\mathrm{CLP} \quad-\mathrm{BLP}+\mathrm{CLP}$

\begin{tabular}{lllll}
\hline & $\mathbf{0 ~ h}$ & $\mathbf{2 ~ h}$ & $\mathbf{6 ~ h}$ & $\mathbf{1 2 ~ h}$ \\
\hline normal & $0.595 \pm 0.037$ & & & \\
\hline sham & & $0.427 \pm 0.128$ & $0.501 \pm 0.063$ & $0.569 \pm 0.057$ \\
\hline CLP & & $0.376 \pm 0.028$ & $0.164 \pm 0.044^{\dagger}$ & $0.132 \pm 0.022^{\dagger}$ \\
\hline BLP + CLP & $0.468 \pm 0.059^{*}$ & $0.234 \pm 0.027^{\# \S}$ & $0.084 \pm 0.019^{\#}$ & $0.262 \pm 0.050^{\# \S}$ \\
\hline
\end{tabular}

$* p<0.05 B L P+C L P$ vs. the normal control $(N)$

$\# p<0.05 B L P+C L P$ vs. the sham control

$\$ p<0.05$ CLP vs. the sham control

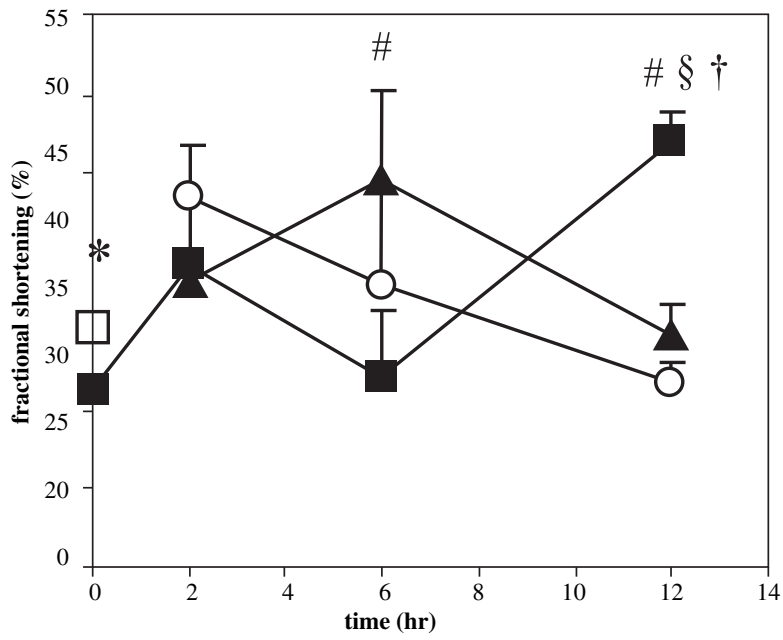

$-\square-\mathrm{N} \quad \longrightarrow$ sham $-\mathrm{O}-\mathrm{CLP} \quad-\mathrm{BLP}+\mathrm{CLP}$

\begin{tabular}{lcccc} 
& $\mathbf{0 ~ h}$ & $\mathbf{2 ~ h}$ & $\mathbf{6 ~ h}$ & $\mathbf{1 2 ~ h}$ \\
\hline normal & $35.214 \pm 1.159$ & & & \\
\hline sham & & $38.303 \pm 4.441$ & $44.697 \pm 5.544$ & $34.864 \pm 1.928$ \\
\hline CLP & & $43.433 \pm 3.378$ & $37.920 \pm 5.975$ & $31.590 \pm 1.410^{\dagger}$ \\
\hline BLP+CLP & $31.242 \pm 0.596^{*}$ & $39.234 \pm 3.644$ & $32.020 \pm 4.254^{\#}$ & $46.992 \pm 1.961^{\# \S}$ \\
\hline
\end{tabular}

$* p<0.05 B L P+C L P$ vs. the normal control $(N)$

\# $p<0.05 B L P+C L P$ vs. the sham control

$p<0.05 B L P+C L P$ vs. CLP
$p<0.05$ CLP vs. the sham control

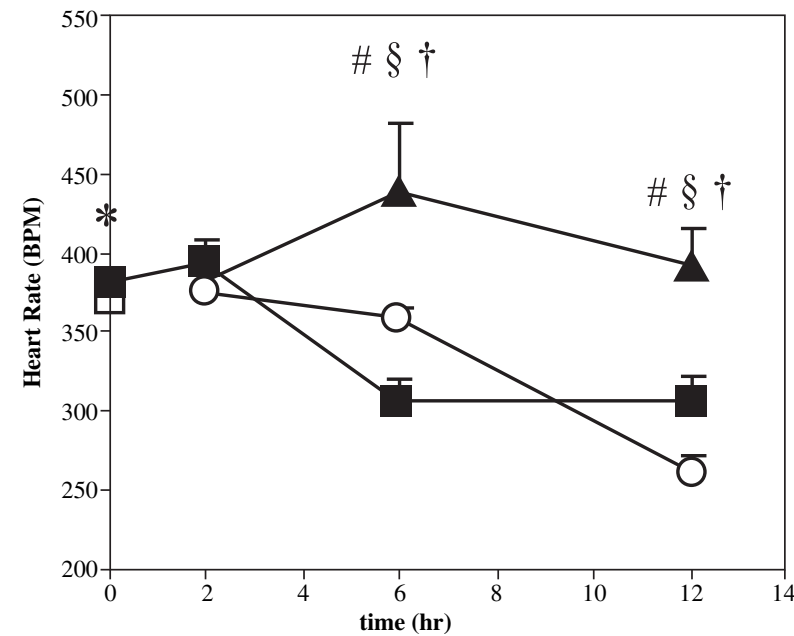

\begin{tabular}{|c|c|c|c|c|}
\hline & \multirow{2}{*}{$\begin{array}{r}-\square-\mathrm{N} \\
\mathbf{0} \mathbf{h}\end{array}$} & - sham & $\rightarrow-1$ & $\mathrm{BLP}+\mathrm{CLP}$ \\
\hline & & $2 \mathrm{~h}$ & $6 \mathrm{~h}$ & $12 \mathrm{~h}$ \\
\hline normal & $367.835 \pm 6.250$ & & & \\
\hline sham & & $382.431 \pm 16.205$ & $438.287 \pm 43.269$ & $391.863 \pm 23.028$ \\
\hline CLP & & $375.830 \pm 18.313$ & $358.638 \pm 7.122^{\dagger}$ & $261.103 \pm 9.826^{\dagger}$ \\
\hline $\mathrm{BLP}+\mathrm{CLP}$ & $380.453 \pm 5.445^{*}$ & $393.647 \pm 15.228$ & $306.278 \pm 14.369^{\# \S}$ & $306.340 \pm 16.322^{\#}$ \\
\hline
\end{tabular}

Fig. 2. BLP tolerance prevented cardiac dysfunction in CLP-induced septic mice. Echocardiographic parameters were examined at time $0 \mathrm{~h}, 2 \mathrm{~h}, 6 \mathrm{~h}$ and $12 \mathrm{~h}$ after CLP. There were five mice in each group 


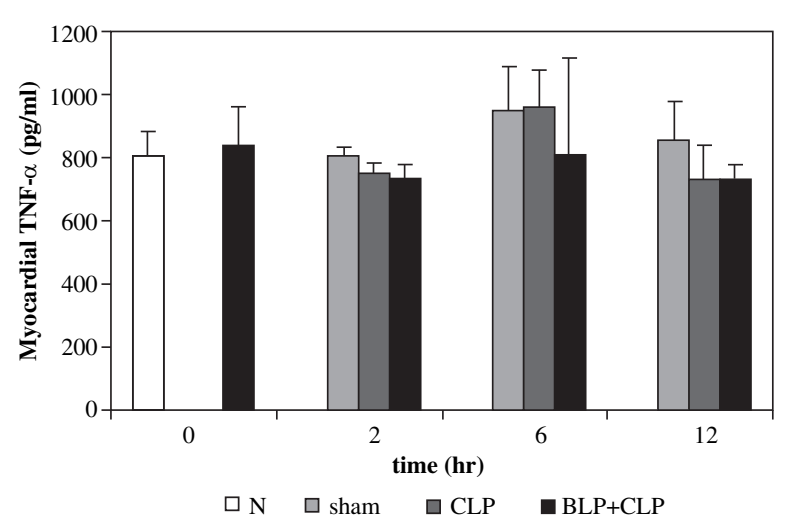

\begin{tabular}{lcccc}
\hline & $\mathbf{0 h}$ & $\mathbf{2 h}$ & $\mathbf{6 h}$ & $\mathbf{1 2} \mathbf{h}$ \\
\hline normal & $805.37 \pm 78.62$ & & & \\
\hline sham & & $805.04 \pm 29.42$ & $950.43 \pm 140.97$ & $857.12 \pm 121.55$ \\
\hline CLP & & $751.54 \pm 31.29$ & $963.63 \pm 111.66$ & $733.14 \pm 104.81$ \\
\hline BLP + CLP & $838.09 \pm 123.00$ & $735.85 \pm 43.16$ & $807.88 \pm 310.98$ & $735.85 \pm 43.16$
\end{tabular}

Fig. 3. Time course of myocardial TNF- $\alpha$ production. pTNF- $\alpha$ levels in the myocardial cytoplasmic proteins were determined using ELISA kits. ELISA data are expressed as mean $\pm \mathrm{SE}$, $n=3$ in each time point

apoptosis in mouse cardiomyocytes increased rapidly, with no significant changes in the BLP-tolerance mice at the corresponding time points. These results imply that BLP tolerance may induce apoptosis in cardiomyocytes, but may delay apoptosis triggered by CLP.

\section{Discussion}

BLP tolerance attenuated LV cardiac dysfunction in mice with CLP-induced sepsis. BLP attenuation of cardiac dysfunction had no significant correlation with TNF- $\alpha$, IL-10 or TLR2-mediated signaling in the myocardium, however BLP tolerance can delay CLP-triggered apoptosis in the mouse myocardium.

Septic shock is a serious problem that is routinely encountered in the intensive care units of hospitals. Despite effective antibiotics, the lethality of septic shock remains high [19]. This problem is likely to increase as more aggressive treatment strategies are used in immunosuppressed patients. Although knowledge of the pathophysiology of septic shock continuously increases, its complexity is far from being understood. It is, however, accepted that once invading bacteria have triggered septic shock, therapeutic interventions may often be too late. Strategies thus need to be developed to prevent the pathophysiological response of the infected host [20].

The CLP septic shock model used in the present study is a hypodynamic sepsis model that is characterized by reduced $\mathrm{CO}$ and EF. In this study, CLP induced a progres-

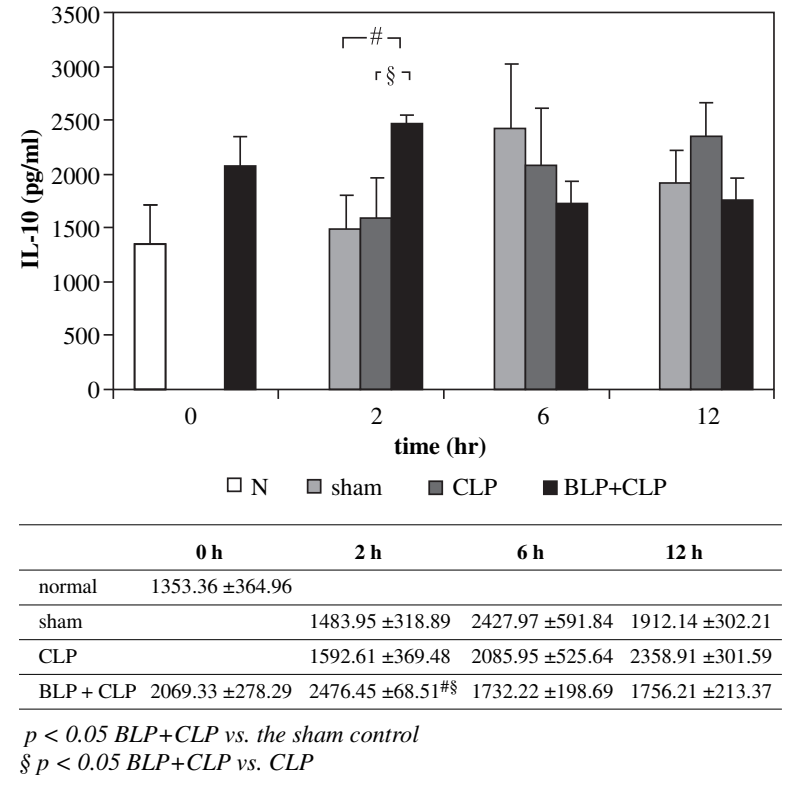

Fig. 4. Time course of myocardial IL-10 production. p IL-10 levels in the myocardial cytoplasmic proteins were determined using ELISA kits. ELISA data are expressed as means \pm SE, $n=3$ in each time point

sive decrease in FS, CO and HR from $2 \mathrm{~h}$ to $12 \mathrm{~h}$ following surgery. At the same time, we observed a slight increase in EF between 2 and $6 \mathrm{~h}$ after CLP, and an abrupt decrease between 6 and $12 \mathrm{~h}$.

In vivo, tolerance induced by BLP can protect mice against not only lethality, but also LPS-, live bacterial-, and polymicrobial sepsis-induced lethality [11]. In vitro, THP-1 cells are pretreated with a low dose of BLP for $24 \mathrm{~h}$ and then subjected to a second stimulation with the same or higher doses of BLP. This causes TNF- $\alpha$ production to be reduced significantly $[14,15]$. Experimental and clinical studies have shown that harmful tissue events, including infections, are perceived by macrophages and monocytes, which in turn secrete pro-inflammatory cytokines such as TNF- $\alpha$, IL-1 $\beta$, IL-6, IL-12 and antiinflammatory cytokines such as IL-4, IL-10 [11, 21-23]. Appropriate levels of these cytokines are essential for cellmediated microbicidal activity as excessive production can lead to an uncontrolled inflammatory response, multiple organ failure, and ultimately death [11]. Experimental studies support a critical role for enhanced production of inflammatory cytokines in the development of sepsis-induced myocardial dysfunction [21, 24-26]. Meanwhile, cardiac tissues synthesize TNF- $\alpha$, IL-1 $\beta$, and IL-10 [5, 27-31] and increase the local production of cytokines, which has been implicated in myocardial dysfunction observed during several pathological conditions [5, 30-32]. Therefore, we postulated that BLP administration could also improve myocardial function in the sepsis mice. To evaluate this hypothesis, 


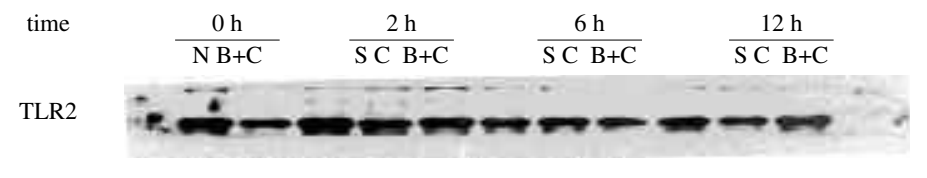

MyD88

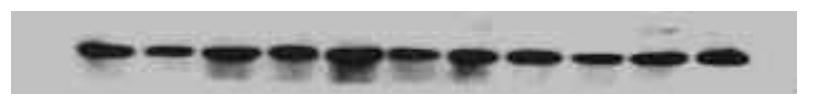

IRAK-1

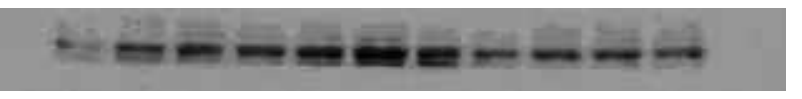

TRAF6

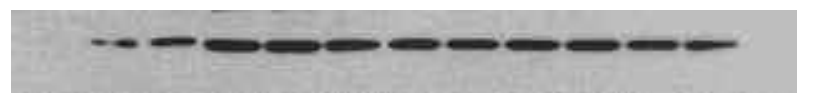

$\alpha$-tubulin
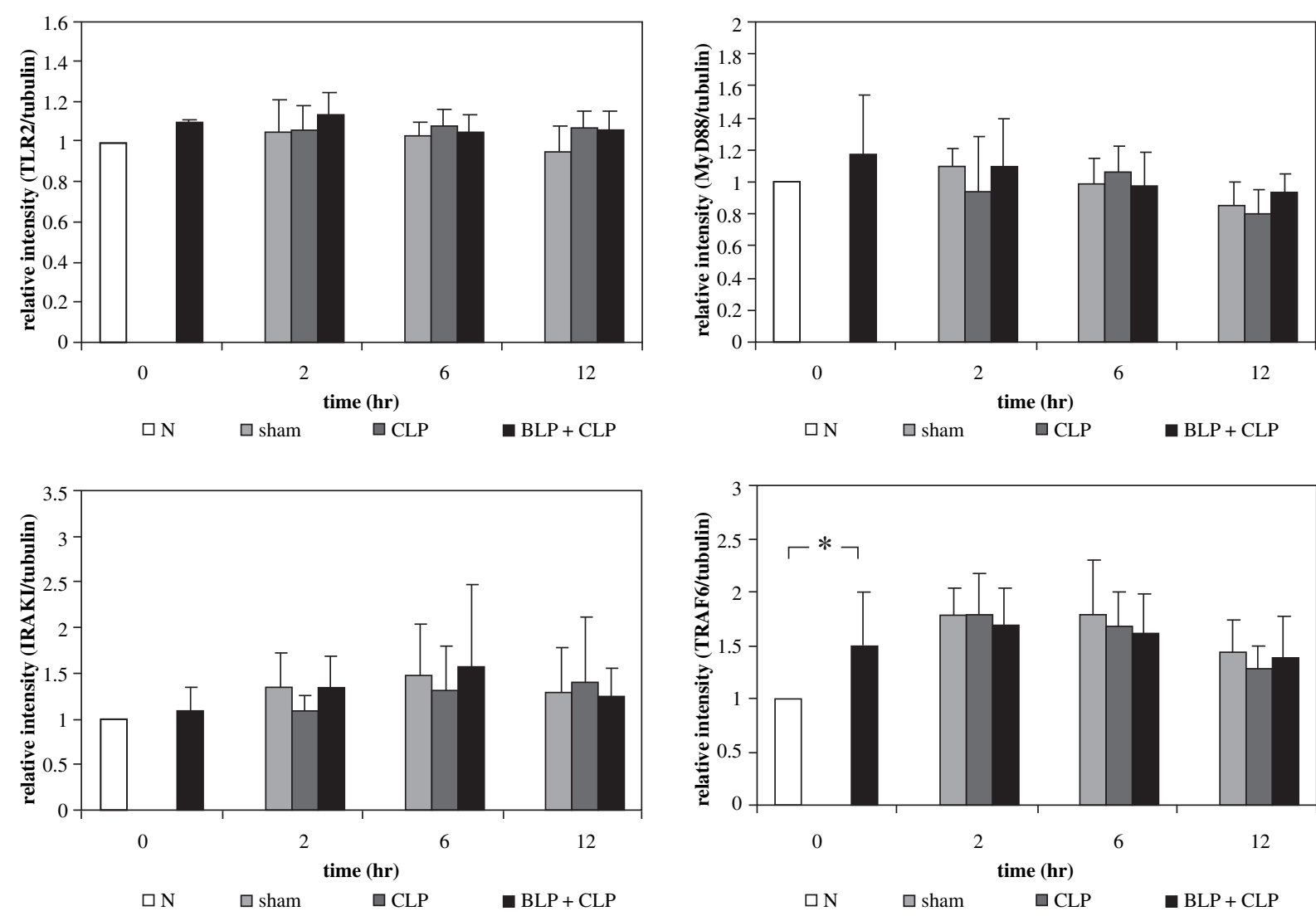

$* p<0.05 B L P+C L P$ versus the normal control $(N)$. Results shown represent one experiment from a total of three independent experiments.

Fig. 5. Influence of BLP tolerance on the expression of the TLR2, MyD88, IRAK-1, TRAF6 in the myocardium of BLP-tolerant and non-tolerant septic mice. pTRAF6 protein expression by western blot analysis. There were three mice in each time point

cardiac function and myocardial TNF- $\alpha$ and IL-10 levels in cytoplasmic proteins were measured from septic mice with or without BLP tolerance. We showed that cardiac function was significantly depressed in BLP-tolerant septic mice at $2 \mathrm{~h}$ and $6 \mathrm{~h}$ following CLP, and returned to the baseline at $12 \mathrm{~h}$. BLP-tolerant septic mice cardiac function was signif- icantly improved compared to that of non-tolerant septic mice at $12 \mathrm{~h}$. Therefore, low dose BLP pretreatment resulted in enhanced cardiac function and increased survival in septic mice. However, myocardial IL-10 levels were significantly increased in the BLP tolerant septic mice as compared with those of the sham group and non-tolerant septic 

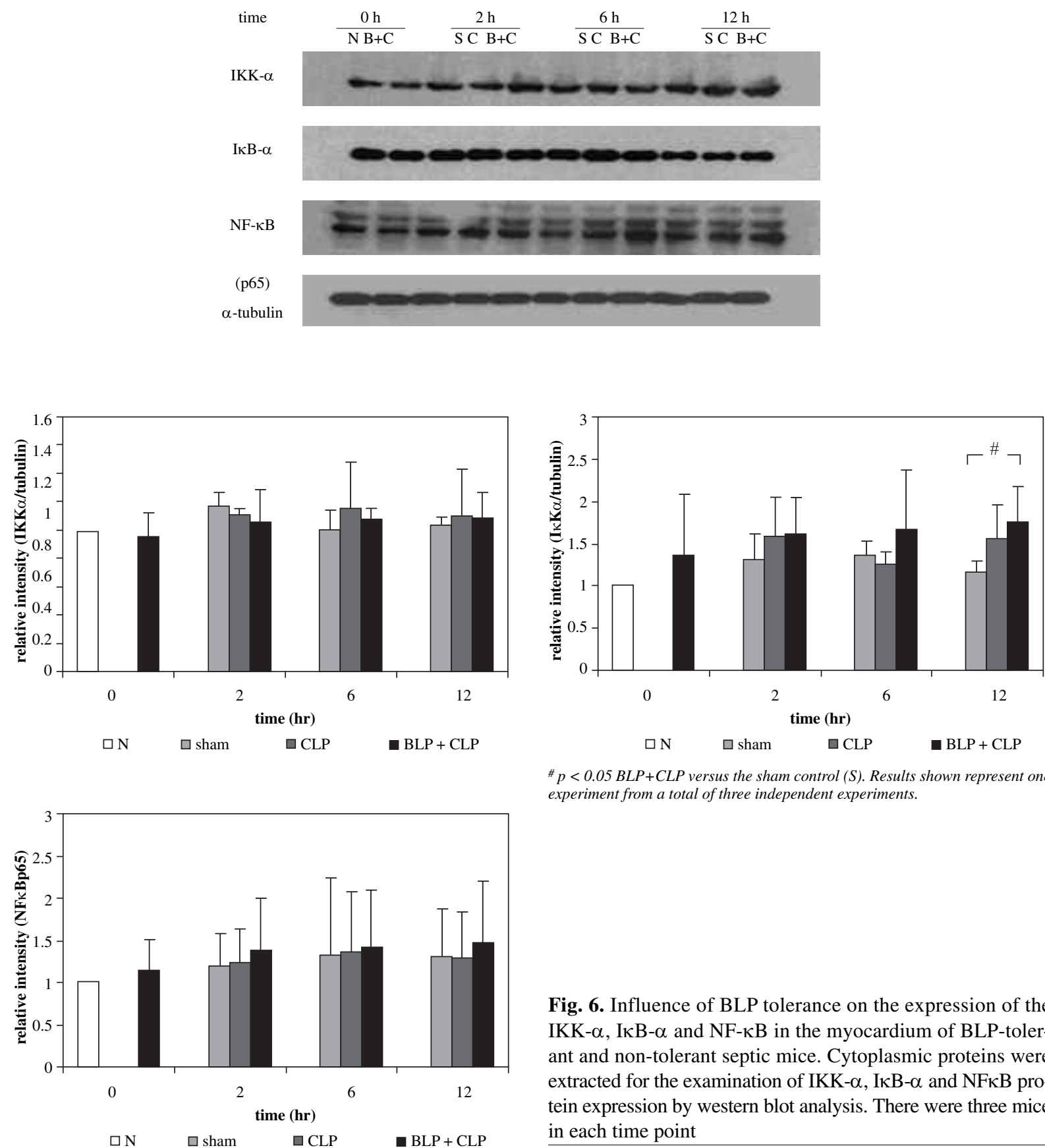

\# $p<0.05 B L P+C L P$ versus the sham control $(S)$. Results shown represent one experiment from a total of three independent experiments.

Fig. 6. Influence of BLP tolerance on the expression of the IKK- $\alpha$, I $\kappa \mathrm{B}-\alpha$ and NF- $\kappa \mathrm{B}$ in the myocardium of BLP-tolerant and non-tolerant septic mice. Cytoplasmic proteins were

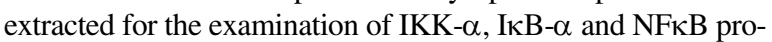
tein expression by western blot analysis. There were three mice in each time point

mice at $2 \mathrm{~h}$ following CLP. No association between cardiac function and TNF- $\alpha$ or IL-10 levels in the myocardial cytoplasmic proteins at other time points have been determined. BLP tolerance can significantly reduce the serum levels of TNF- $\alpha$, IL-6, and IL-10 in mice challenged with microbial sepsis [9]; therefore, it is likely that enhanced cardiac function observed in BLP-tolerant septic mice is mediated by the depression of circulating inflammatory cytokine expression, which is the basis for further research in our laboratory.

TLRs are pattern recognition receptors (PPRs), which recognize distinct molecular patterns associated with microbial pathogens $[12,13]$. For example, TLR2 is involved in gram-positive BLP stimulation, and TLR4 is required for gram-negative LPS signaling. Upon engagement by different microbial ligands, TLRs are activated and initiate a cascade of intracellular signaling that eventually result in inflammatory cytokine production. TLR2 recruits MyD88dependent pathways $[13,33]$. In vitro, Western blot analy- 
sham
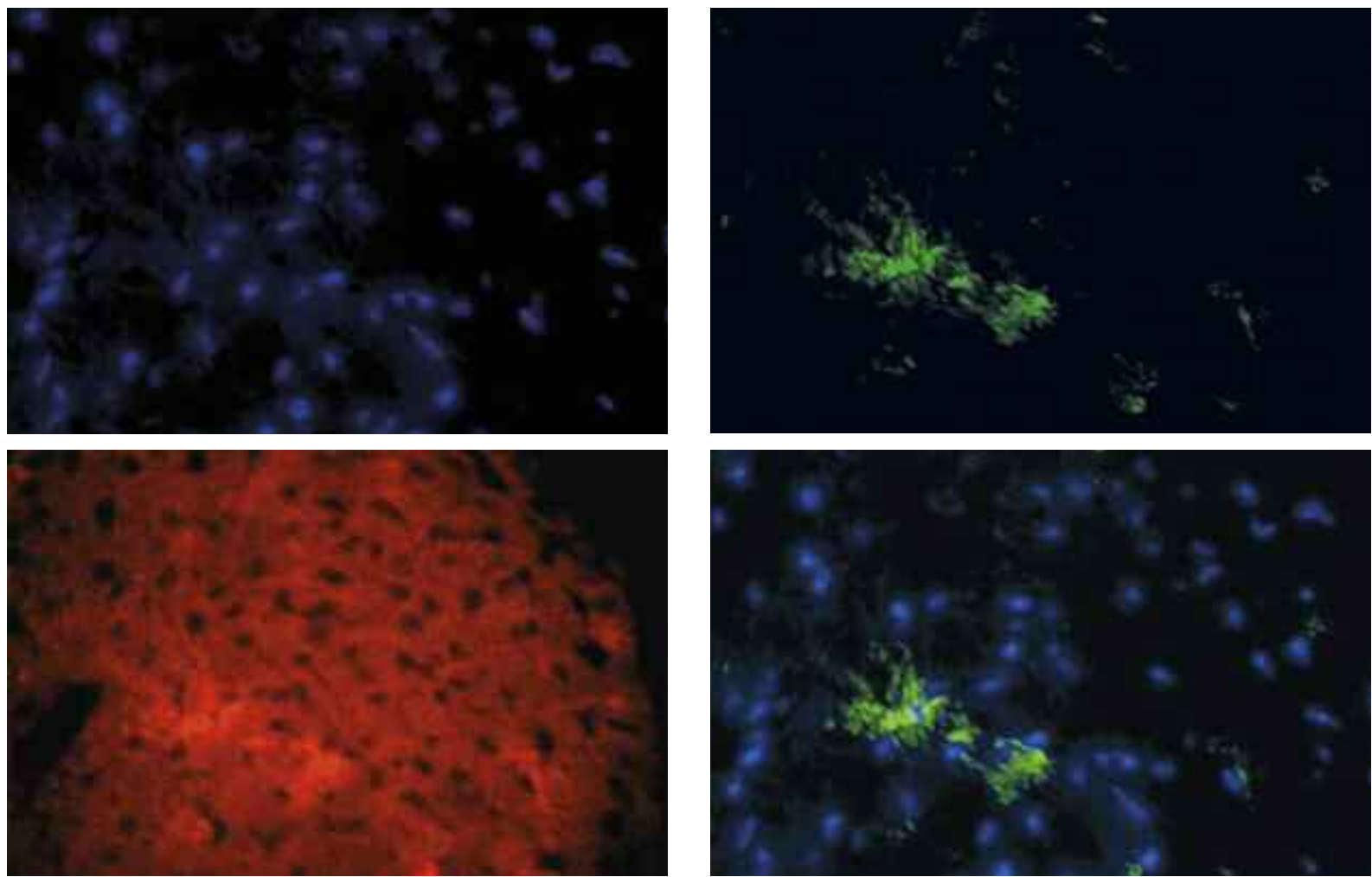

sham
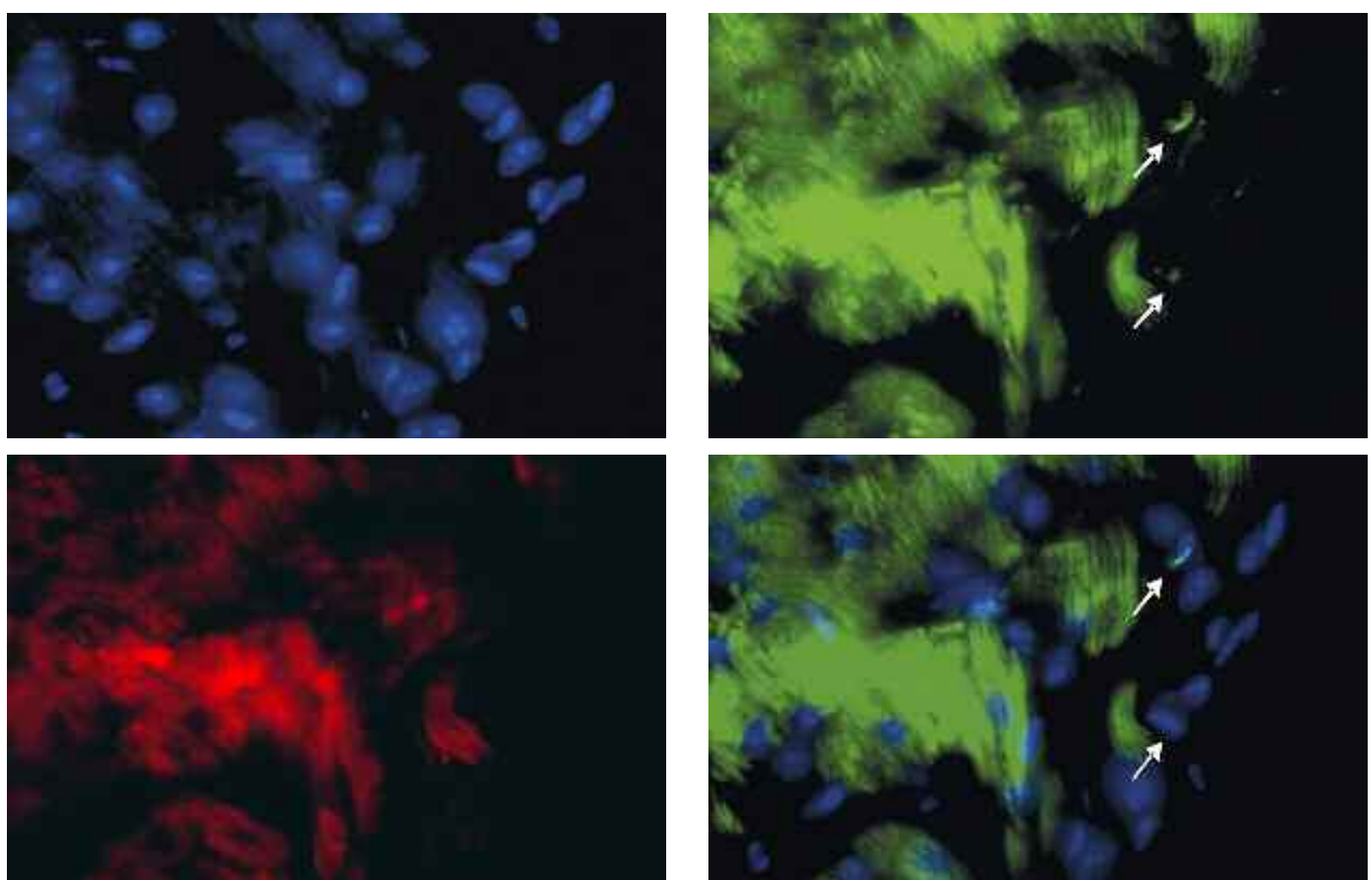

Fig. 7. Effects of BLP tolerance on cardiomyocyte apoptosis. CLP-induced apoptosis was determined by the TUNEL assay. Hearts were harvested at $0,2,6,12 \mathrm{~h}$, and fixed and cut into $4 \mu \mathrm{m}$ serial paraffin sections, respectively. The fluorescence images were captured from the left ventricular free wall. $\alpha$-actinin was used to confirm that the cells were myocytes. Representative images were from three independent experiments. $\rightarrow$ indicates positive nuclei of TUNEL staining. Magnification 1000× Continued on next page 


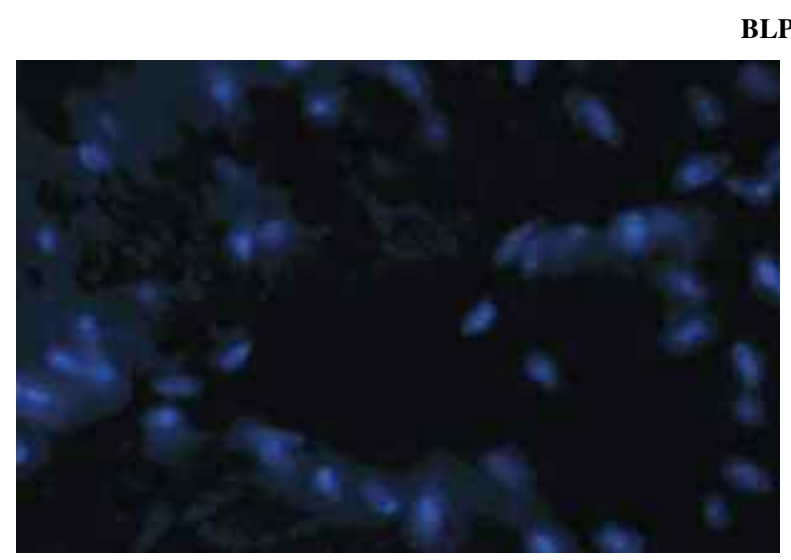

BLP+CLP
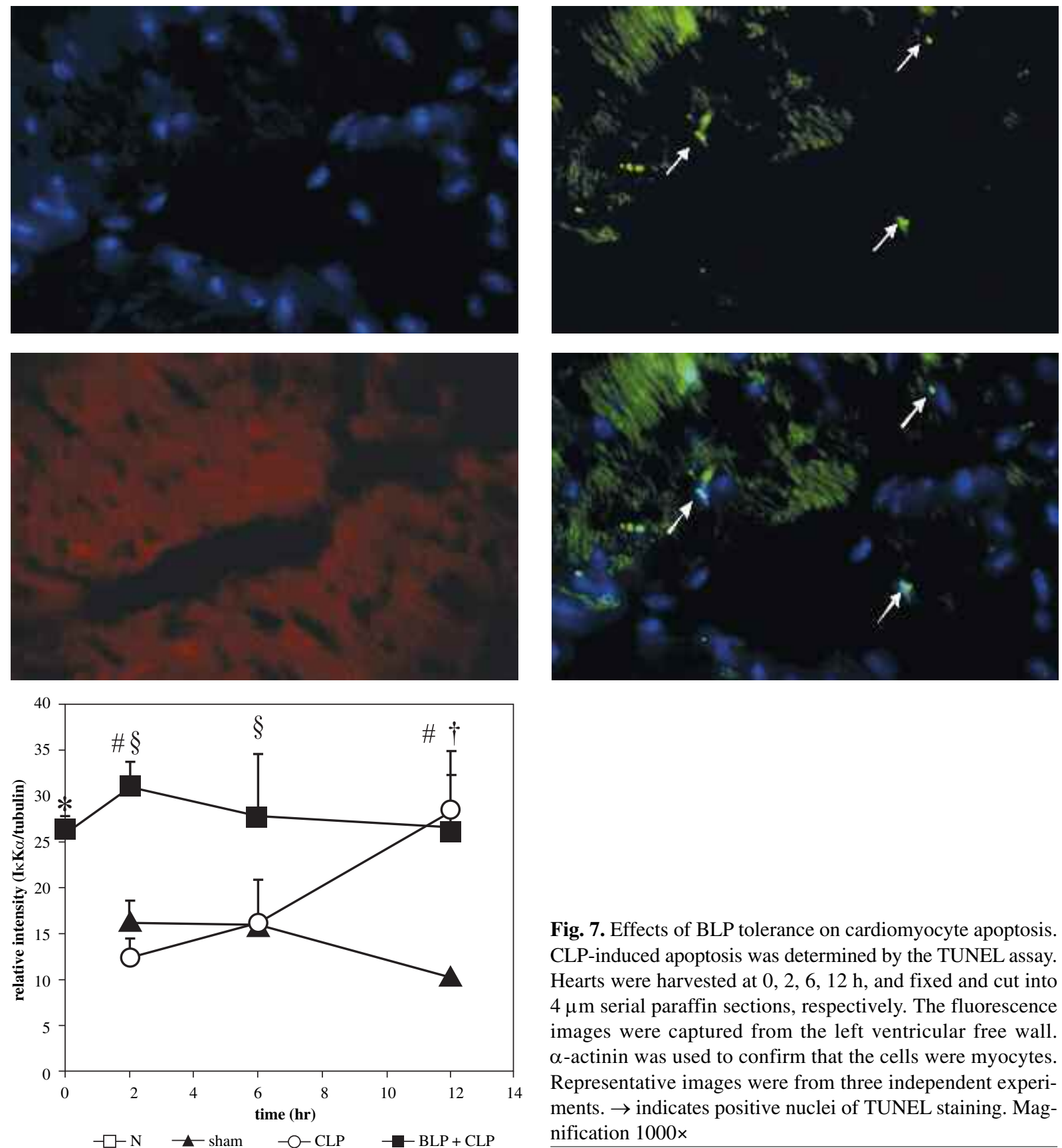

Fig. 7. Effects of BLP tolerance on cardiomyocyte apoptosis. CLP-induced apoptosis was determined by the TUNEL assay. Hearts were harvested at 0,2, 6, $12 \mathrm{~h}$, and fixed and cut into $4 \mu \mathrm{m}$ serial paraffin sections, respectively. The fluorescence images were captured from the left ventricular free wall. $\alpha$-actinin was used to confirm that the cells were myocytes. Representative images were from three independent experiments. $\rightarrow$ indicates positive nuclei of TUNEL staining. Magnification $1000 \times$

sis demonstrated that there was a slight reduction in TLR2 expression in BLP-tolerant THP-1 cells and there were no significant alterations in protein levels of MyD88, IRAK4, or TRAF6 in nad've and BLP-tolerant cells, before or after BLP or LPS stimulation. Similarly, mRNA levels of TLR2 and TLR2 downstream signaling intermediates were not regulated significantly by BLP or LPS stimulation in nadve or BLP-tolerant cells by quantitative real-time RT-PCR analysis [13].

Recent studies have shown that TLR2 is expressed in the myocardium [29, 34-36]. In the present study, we observed a relationship between cardiac function and myocardial TLR2 signaling in septic mice. Although cardiac function was significantly depressed in CLP mice, there were no significant differences between BLP-tolerant and non-tolerant mice before or after a subsequent polymicrobial challenge. Therefore, despite the critical function of the TLR2-MyD88-dependent downstream pathway in trans- 
ducing BLP signaling, it appears that the majority of this pathway is not changed in the regulation of myocardial innate immunity in BLP-tolerant or non-tolerant septic mice.

Studies have shown that endotoxin-induced activation of apoptotic pathways may directly lead to myocardial dysfunction, and inhibition of cardiac apoptosis has been shown to be beneficial in clinically relevant animal models of sepsis $[37,38]$. Our study demonstrates that BLP tolerance and CLP challenge also induced apoptosis in cardiomyocytes, but the CLP-triggered apoptosis in BLP-tolerant mice was delayed further than non-tolerant mice. These data may explain why BLP tolerance attenuated LV cardiac dysfunction in mice with CLP-induced sepsis.

In summary, our data demonstrate that BLP pretreatment can attenuate cardiac dysfunction in CLP-induced sepsis. TNF- $\alpha$, IL-10 or TLR2-MyD88-dependent signaling levels in the myocardium do not contribute to the depression of cardiac function in CLP-induced sepsis, however BLP tolerance can delay CLP-triggered apoptosis in the mouse myocardium.

This work was supported by the Jiangsu Natural Science Fund and the Basic Research Project from the Jiangsu Health Department of China (to S. Zhou). This work was also supported in part by the Jiangsu "135" Key Medical Project of China.

\section{References}

1. Angus DC, Linde-Zwirble WT, Lidicker J, et al. (2001): Epidemiology of severe sepsis in the United States: analysis of incidence, outcome, and associated costs of care. Crit Care Med 29: 1303-1310.

2. Chopra M, Sharma AC (2007): Distinct cardiodynamic and molecular characteristics during early and late stages of sepsis-induced myocardial dysfunction. Life Sci 81: 306-316.

3. Krishnagopalan S, Kumar A, Parrillo JE (2002): Myocardial dysfunction in the patient with sepsis. Curr Opin Crit Care 8: 376-388.

4. Oberholzer A, Oberholzer C, Moldawer LL (2001): Sepsis syndromes: understanding the role of innate and acquired immunity. Shock 16: 83-96.

5. Chagnon F, Metz CN, Bucala R, Lesur O (2005): Endotoxininduced myocardial dysfunction: effects of macrophage migration inhibitory factor neutralization. Circ Res 96: 1095-1102.

6. Court O, Kumar A, Parrillo JE (2002): Clinical review: Myocardial depression in sepsis and septic shock. Crit Care 6: 500-508.

7. Zanotti-Cavazzoni SL, Hollenberg SM (2009): Cardiac dysfunction in severe sepsis and septic shock. Curr Opin Crit Care 15: 392-397.

8. Lorts A, Burroughs T, Shanley TP (2009): Elucidating the role of reversible protein phosphorylation in sepsis-induced myocardial dysfunction. Shock 32: 49-54.

9. Aliprantis A, Yang R, Mark M, et al. (1999): Cell activation and apoptosis by bacterial lipoproteins through toll-like receptor-2. Science 285: 736.

10. Zhang H, Peterson JW, Niesel DW, Klimpel GR (1997): Bacterial lipoprotein and lipopolysaccharide act synergistically to induce lethal shock and proinflammatory cytokine production. J Immunol 159: 4868-4878.
11. Wang JH, Doyle M, Manning BJ, et al. (2003): Cutting edge: bacterial lipoprotein induces endotoxin-independent tolerance to septic shock. J Immunol 170: 14-18.

12. Iwasaki A, Medzhitov R (2004): Toll-like receptor control of the adaptive immune responses. Nat Immunol 5: 987-995.

13. Akira S, Takeda K, Kaisho T (2001): Toll-like receptors: critical proteins linking innate and acquired immunity. Nat Immunol 2: 675-680.

14. Wang J, Doyle M, Manning B, et al. (2002): Induction of bacterial lipoprotein tolerance is associated with suppression of toll-like receptor 2 expression. J Biol Chem 277: 36068-36075.

15. Li CH, Wang JH, Redmond HP (2006): Bacterial lipoproteininduced self-tolerance and cross-tolerance to LPS are associated with reduced IRAK-1 expression and MyD88-IRAK complex formation. J Leukoc Biol 79: 867-875.

16. Neilan TG, Jassal DS, Perez-Sanz TM, et al. (2006): Tissue Doppler imaging predicts left ventricular dysfunction and mortality in a murine model of cardiac injury. Eur Heart J 27: 18681875.

17. Sebag IA, Handschumacher MD, Ichinose F, et al. (2005): Quantitative assessment of regional myocardial function in mice by tissue Doppler imaging: comparison with hemodynamics and sonomicrometry. Circulation 111: 2611-2616.

18. Li C, Browder W, Kao RL (1999): Early activation of transcription factor NF-kappaB during ischemia in perfused rat heart. Am J Physiol 276: H543-552.

19. Glauser MP, Zanetti G, Baumgartner JD, Cohen J (1991): Septic shock: pathogenesis. Lancet 338: 732-736.

20. Dankesreiter S, Hoess A, Schneider-Mergener J, et al. (2000): Synthetic endotoxin-binding peptides block endotoxin-triggered TNF-alpha production by macrophages in vitro and in vivo and prevent endotoxin-mediated toxic shock. J Immunol 164: 4804-4811.

21. Iseri SO, Sener G, Saglam B, et al. (2005): Oxytocin protects against sepsis-induced multiple organ damage: role of neutrophils. J Surg Res 126: 73-81.

22. Bhatia M (2005): Inflammatory response on the pancreatic acinar cell injury. Scand J Surg 94: 97-102.

23. Jaworek J, Konturek S, Macko M, et al. (2007): Endotoxemia in newborn rats attenuates acute pancreatitis at adult age. J Physiol Pharmacol 58: 131-147.

24. Rudiger A, Singer M (2007): Mechanisms of sepsis-induced cardiac dysfunction. Crit Care Med 35: 1599-1608.

25. Jean-Baptiste E (2007): Cellular mechanisms in sepsis. J Intensive Care Med 22: 63-72.

26. Niu J, Azfer A, Kolattukudy P (2008): Protection against lipopolysacharide-induced myocardial dysfunction in mice by cardiac-specific expression of soluble Fas. J Mol Cell Cardiol 2008; 44: 160-169.

27. Mann DL (1996): Stress activated cytokines and the heart. Cytokine Growth Factor Rev 7: 341-354.

28. Horton JW, Maass DL, White J, Sanders B (2001): Hypertonic saline-dextran suppresses burn-related cytokine secretion by cardiomyocytes. Am J Physiol Heart Circ Physiol 280: H1591-1601.

29. Frantz S, Kobzik L, Kim YD, et al. (1999): Toll4 (TLR4) expression in cardiac myocytes in normal and failing myocardium. J Clin Invest 104: 271-280.

30. Patten M, Kramer E, Bunemann J, et al. (2001): Endotoxin and cytokines alter contractile protein expression in cardiac myocytes in vivo. Pflugers Arch 442: 920-927.

31. Horton JW, Maass DL, White J, Sanders B (2003): Myocardial inflammatory responses to sepsis complicated by previous burn injury. Surg Infect (Larchmt) 4: 363-377. 
32. Fentzke RC, Korcarz CE, Lang RM, et al. (1998): Dilated cardiomyopathy in transgenic mice expressing a dominant-negative CREB transcription factor in the heart. J Clin Invest 101: 2415-2426.

33. Mitchell JA, Paul-Clark MJ, Clarke GW, et al. (2007): Critical role of toll-like receptors and nucleotide oligomerisation domain in the regulation of health and disease. J Endocrinol 193: 323-330.

34. Zarember KA, Godowski PJ (2002): Tissue expression of human Toll-like receptors and differential regulation of Tolllike receptor mRNAs in leukocytes in response to microbes, their products, and cytokines. J Immunol 168: 554-561.

35. Baumgarten G, Knuefermann P, Nozaki N, et al. (2001): In vivo expression of proinflammatory mediators in the adult heart after endotoxin administration: the role of toll-like receptor4. J Infect Dis 183: 1617-1624.

36. Knuefermann P, Sakata Y, Baker JS, et al. (2004): Toll-like receptor 2 mediates Staphylococcus aureus-induced myocardial dysfunction and cytokine production in the heart. Circulation 110: 3693-3698.

37. Wang X, Zingarelli B, O'Connor M, et al. (2009): Overexpression of Hsp20 prevents endotoxin-induced myocardial dysfunction and apoptosis via inhibition of NF-kappaB activation. J Mol Cell Cardiol 47: 382-390.

38. Lancel S, Joulin O, Favory R, et al. (2005): Ventricular myocyte caspases are directly responsible for endotoxininduced cardiac dysfunction. Circulation 111: 2596-2604. 